\title{
Experiences of Attending Group Education to Support Insulin Initiation in Type 2 Diabetes: A Qualitative Study
}

\author{
Rebecca Upsher (D) - Maya Allen-Taylor · Ilse Reece • Mark Chamley • \\ Khalida Ismail · Angus Forbes · Kirsty Winkley
}

Received: September 5, 2019 / Published online: November 15, 2019

(C) The Author(s) 2019

\begin{abstract}
Introduction: Type 2 diabetes is a progressive condition and many people require insulin therapy 5-10 years post diagnosis. Considering the global increase in type 2 diabetes, group education programmes to initiate insulin are beneficial as they are cost-effective and provide peer support. However, group education to initiate insulin has not been widely evaluated and there is a need to elicit the views and experience of people with type 2 diabetes who start insulin in groups. The aim of this study was to explore the perspectives of people with type 2 diabetes
\end{abstract}

Enhanced Digital Features To view enhanced digital features for this article go to https://doi.org/10.6084/ m9.figshare.10108478.

R. Upsher $(\varangle) \cdot$ K. Ismail

Diabetes, Psychiatry, and Psychology, Department of Psychological Medicine, King's College London and Institute of Psychiatry, Psychology and

Neuroscience, London, UK

e-mail: rebecca.j.upsher@kcl.ac.uk

M. Allen-Taylor · I. Reece · A. Forbes - K. Winkley Florence Nightingale Faculty of Nursing and Midwifery and Palliative Care, King's College London, London, UK

M. Chamley

Lambeth Clinical Commissioning Group Diabetes Intermediate Care Team, South London, London, UK who receive nurse-led group-based insulin education.

Methods: Qualitative, semi-structured interviews of people with type 2 diabetes in south London, UK, who had attended group education sessions to start insulin. Inductive thematic analysis identified themes within the data.

Results: Fifteen people with type 2 diabetes were interviewed. Three main themes were identified: creating a supportive environment; facilitator skills; and effectiveness of group. Factors which created a supportive environment included peer support, providing reassurance and printed materials. Facilitator skills associated with positive experiences included addressing negative insulin beliefs and managing group dynamics. The effectiveness of the group was determined by ongoing self-management success, need for more peer support, and insulin concerns post insulin education group.

Conclusion: Positive experiences of insulin group education for people with type 2 diabetes were associated with sharing experiences with other people starting insulin, reassurance from healthcare professionals, appropriate supportive materials, and skill of the facilitator to address insulin concerns and manage group dynamics. People with type 2 diabetes may benefit more from education if healthcare professionals are skilled in psychological techniques to facilitate group education aimed at addressing concerns around insulin therapy. Further research needs 
to assess the effectiveness of structured insulin group education for people with type 2 diabetes.

Keywords: Diabetes nurse; Education; Health care delivery; Insulin therapy; Psychological aspects; Self-management; Type 2 diabetes

\section{Key Summary Points}

\section{Why carry out this study?}

There is global increase in the number of people with type 2 diabetes and as a result of its progressive nature more people will require insulin injection therapy.

Group education is a cost-effective approach to starting insulin requiring fewer diabetes nurse specialist educators.

This study aims to explore the perspectives of people with type 2 diabetes of group-based insulin education.

\section{What was learned from the study?}

This qualitative research demonstrates that peer support and appropriate resources aid group insulin initiation education.

However, concerns following insulin education suggest that improvement is required and some nurses require training to address anxiety around insulin therapy.

Further work is needed to make insulin initiation groups equitable to all.

\section{INTRODUCTION}

There are an estimated 422 million people with type 2 diabetes living with diabetes worldwide [1], costing world healthcare services over 827 billion US dollars [2, 3]. Type 2 diabetes is a progressive condition if not managed intensively with weight-loss strategies from diagnosis [4], and which are not achievable for many people. And even with optimal glycaemic control and appropriate medication regimes, beta cell function deteriorates over time [5]. Therefore, a large proportion of people with type 2 diabetes require insulin injections around 5-10 years from diagnosis, a treatment which is associated with improved glycaemic control [6] and reduced risk of diabetes complications [7]. With the growing population of type 2 diabetes, there has been a shift from initiating and managing insulin in secondary care to primary care [8]. However, a recent UK survey found a shortage of diabetes specialists nurses/educators, fewer qualified nurses recruited into diabetes specialist roles, and an estimated $57 \%$ of diabetes specialist nurses due to retire within 10 years [9]. Additionally, primary care nurses who are trained to support people with insulin education are also a limited resource. There is a similar picture in North America [10]. Therefore, there are fewer diabetes specialist nurses available with specialist skills to initiate insulin. A solution, requiring fewer specialists, is to provide insulin education in groups. Diabetes group education is cost-effective compared with individual support [11].

In the south London borough of Lambeth (UK) there is an existing 'insulin start group' for people with type 2 diabetes newly prescribed insulin therapy. The group comprises two sessions ( $2 \mathrm{~h}$ each) 1 week apart to provide key educational and safety information around initiating and self-managing with insulin. The curriculum includes type 2 diabetes progression; safe insulin administration; insulin storage; dose titration; hypoglycaemia; driving with insulin; blood glucose readings review; sick day rules; travelling with insulin; and interpreting results of annual reviews. There are up to six people per group and are facilitated by diabetes specialist nurses/educators. Referral to these insulin start groups is made by general practitioners in primary care. There is evidence that group education for people with type 2 diabetes can improve diabetes self-management and glycaemic control [12-16], and is viewed favourably by healthcare professionals [17]. However, the evidence is for diabetes self-management education in general; less is known about type 2 diabetes insulin education groups. 
People with type 2 diabetes have reported many negative beliefs around insulin therapy $[14,18,19]$, termed psychological insulin resistance [20-22], which include sense of personal failure [23]; social stigma [24]; and fears of injections [25], lifestyle change [26], side effects, complications [25], and weight gain [27]. People with type 2 diabetes are likely to discontinue insulin if concerns are not addressed [28]. However, there is currently no national or international guidance on how to address insulin concerns for people with type 2 diabetes [29] which could be incorporated into education groups to provide optimal support.

In summary, insulin education groups are useful to reduce cost burden for health services and maximise the expertise of diabetes specialist nurses as the number of people with type 2 diabetes continues to rise. Therefore, it is important to gauge the views of people with type 2 diabetes who have attended insulin education groups to identify views on the barriers to insulin self-management, and suggestions for additional support to maximise the potential of aiding insulin self-management in type 2 diabetes. The aim of this study was to qualitatively evaluate the experiences of people with type 2 diabetes who had attended an insulin start group in south London.

\section{METHODS}

This study employed a qualitative design using semi-structured one-to-one interviews of people with type 2 diabetes from south London. This qualitative research was reported according to the 'consolidated criteria for reporting qualitative research checklist'. Ethical approval was obtained by King's College Hospital (ref. 17/LO/ 0363). Participants were provided with information sheets before commencing the study, were given time to consider the information and ask the researchersquestions. They were informed of their right to withdraw at any time. Participants signed a consent form. Personal identifiers were removed and cannot be identified in this report. This study was performed in accordance with the Helsinki Declaration of 1964 and its later amendments.

\section{Recruitment and Sample}

English-speaking adults (at least 18 years old) with type 2 diabetes were invited to participate in the study if they had attended an insulin start group in south London and commenced insulin. All participants received the same type of education facilitated by diabetes specialist nurses/educators at community venues in south London after receiving their first insulin prescription. People attending the insulin start groups started on once daily basal insulin, with a starting dose of 10 units which they were taught how to titrate within the group. People with type 2 diabetes were purposively sampled by gender, age ( $\leq 45,46-59,60+$ years), and ethnicity (white, black, South Asian/other).

\section{Development of Interview Schedule}

An initial interview topic guide was designed by three researchers (RU, KW, MA) on the basis of current literature (Table 1). The interview schedule was assessed for face validity through

Table 1 Topic guide for interview schedule

Reasons for referral to diabetes specialist team

Need for insulin, barriers to uptake and adherence

Benefits of insulin

Disadvantages of insulin

Delay in insulin?

Concerns/worries before insulin initiation

Views on insulin self-management support

Views on group insulin education

Positive views on insulin self-management support

Less positive/helpful aspects of insulin self-

management support

Readiness to initiate insulin

Follow-up support

Recommendations for future insulin education support 
discussion with healthcare professionals and piloting the interview on two people with type 2 diabetes who had attended an insulin start group; topics guides were then revised. For subsequent interviews, each researcher listened to audiotapes of interviews conducted by the other two researchers for fidelity purposes, allowing reflection and discussion of interview technique, and to identify any interviewer bias to be eliminated in subsequent interviews. Topic guides were revised as required to account for individual interviewing styles and for rigorous data collection.

\section{Data Collection}

Interviews were conducted by one of the three female researchers who had experience with conducting qualitative research and were based at King's College London; two researchers were also diabetes specialist nurses (MA, KW). Diabetes specialist nurses did not interview any person with diabetes for whom they had personally educated. Eligible participants were identified on Egton Medical Information Systems (medical record system) by diabetes specialist nurses on the research team who were then contacted via telephone and, if willing, arranged a date and time for the interview. Interviewees were given the choice of interview location to maximise recruitment: King's College London research facility or the participants' local general practice surgery.

Participants were informed that the study was funded by the National Institute for Health Research and the specific purpose of the project was to determine views on the barriers to insulin self-management, views on diabetes education courses, and suggestions for additional support to aid insulin self-management in type 2 diabetes. Each participant was interviewed once. To ascertain adequate sample size, after every three interviews, the transcripts were assessed (by RU and KW) for information power based on study aim (views of insulin education received); sample specificity (people who attended an insulin start group and sample based on age, gender and ethnicity); quality of dialogue (assessed by knowledge base of researchers as well as rapport between researcher and participants); and analysis strategy (outlined below) [30].

\section{Data Analysis}

Interviews were transcribed and anonymised data from transcripts were managed in NVivo12 (qualitative computer software). Inductive thematic analysis identified themes within the data via six stages [31]: (1) familiarisation of data by reading of transcripts and listening to audiotapes, making notes of initial impressions; (2) generation of initial codes (RU and MA; reviewed by KW); (3) searching for themes by collating codes that depict the data; (4) reviewing themes and making sure the themes apply accurately to all coded data; (5) defining and naming each theme to describe which aspects of the data the theme represents; (6) producing a final report.

\section{RESULTS}

A total of 15 people with type 2 diabetes were recruited. The mean age was $61.40(\mathrm{SD}=10.58)$, the majority were female $(53.3 \%)$, 60 years or over $(53.3 \%)$, and Black African or Caribbean ethnicity $(60 \%)$ (Tables 2,3$)$. The mean diabetes duration was 11.33 years $(\mathrm{SD}=7.18)$. The mean HbA1c level was $73.53 \mathrm{mmol} / \mathrm{mol}(\mathrm{SD}=21.49)$. Diabetes treatment is reported in Table 2. The most common insulin treatment was Humulin I $(73.3 \%)$, and most common oral antidiabetic medication combination was metformin, gliclazide and sitagliptin (33.3\%). Three people were prescribed glucagon-like peptide 1 treatment. No one dropped out of the study, one person declined to participate (lack of time), and there were three people who were eligible but did not respond to the research team. The mean duration of interviews was $28.10 \mathrm{~min}$ $(\mathrm{SD}=9.82)$.

The analysis generated three key themes: 1 . creating a supportive environment; 2 . facilitator skills; 3 . effectiveness of group. There were further subthemes within each theme (Fig. 1). 
Table 2 Overall demographics of interviewees with type 2 diabetes

\begin{tabular}{llll}
\hline Characteristics & Number & Percentage & Mean (SD) \\
\hline Age & & & $61.40(10.58)$ \\
$\leq 45$ & 2 & 13.3 & \\
$46-59$ & 5 & 33.3 & \\
$60+$ & 8 & 53.3 &
\end{tabular}

Ethnicity

$\begin{array}{lll}\begin{array}{lll}\text { Black African/ } \\ \text { Caribbean }\end{array} & 9 & 60.0 \\ \text { Caucasian } & 5 & 33.3 \\ \text { Asian/other } & 1 & 6.7\end{array}$

Gender

$\begin{array}{lll}\text { Female } & 8 & 53.3 \\ \text { Male } & 7 & 46.7\end{array}$

Diabetes duration

$11.33(7.18)$

HbAlc

$73.53(21.49)$

Insulin type

$\begin{array}{lrl}\text { Humulin I } & 11 & 73.3 \\ \text { Novomix } 30 & 2 & 13.3 \\ \text { Lantus } & 1 & 6.7 \\ \text { Abasaglar } & 1 & 6.7\end{array}$

Oral antidiabetic medications

$\begin{array}{lll}\text { Zero } & 2 & 13.3 \\ \text { Gliclazide only } & 2 & 13.3 \\ \text { Metformin only } & 2 & 13.3 \\ \begin{array}{l}\text { Metformin and } \\ \text { gliclazide }\end{array} & 2 & 13.3 \\ \begin{array}{l}\text { Metformin, } \\ \text { gliclazide, } \\ \text { sitagliptin }\end{array} & 5 & 33.3 \\ \begin{array}{l}\text { Metformin, } \\ \text { gliclazide and } \\ \text { linagliptin }\end{array} & 2 & 13.3 \\ \end{array}$

Glucagon-like peptide-1

$\begin{array}{lll}\text { Zero } & 12 & 80\end{array}$
Table 2 continued

\begin{tabular}{lcll}
\hline Characteristics & Number & Percentage & Mean (SD) \\
\hline Dulaglutide & 2 & 13.3 & \\
Liraglutide & 1 & 6.7 & \\
\hline
\end{tabular}

Table 3 Demographics of each interviewee with type 2 diabetes

\begin{tabular}{llll}
\hline $\begin{array}{l}\text { Participant } \\
\text { number }\end{array}$ & $\begin{array}{l}\text { Age } \\
\text { group }\end{array}$ & Sex & Ethnic group \\
\hline 1 & $46-59$ & Female & Black African/Caribbean \\
2 & $60+$ & Female & Asian/other \\
3 & $60+$ & Female & White \\
4 & $60+$ & Male & White \\
5 & $46-59$ & Female & Black African/Caribbean \\
6 & $60+$ & Male & Black African/Caribbean \\
7 & $\leq 45$ & Male & Black African/Caribbean \\
8 & $46-59$ & Female & White \\
9 & $60+$ & Female & White \\
10 & $60+$ & Female & White \\
11 & $60+$ & Female & Black African/Caribbean \\
12 & $46-59$ & Male & Black African/Caribbean \\
13 & $60+$ & Male & Black African/Caribbean \\
14 & $46-59$ & Male & Black African/Caribbean \\
15 & $\leq 45$ & Male & Black African/Caribbean \\
\hline
\end{tabular}

\section{Creating a Supportive Environment}

An environment which best provided insulin self-management support consisted of three components including group members (peers), group facilitators, and supportive resources (printed materials). 


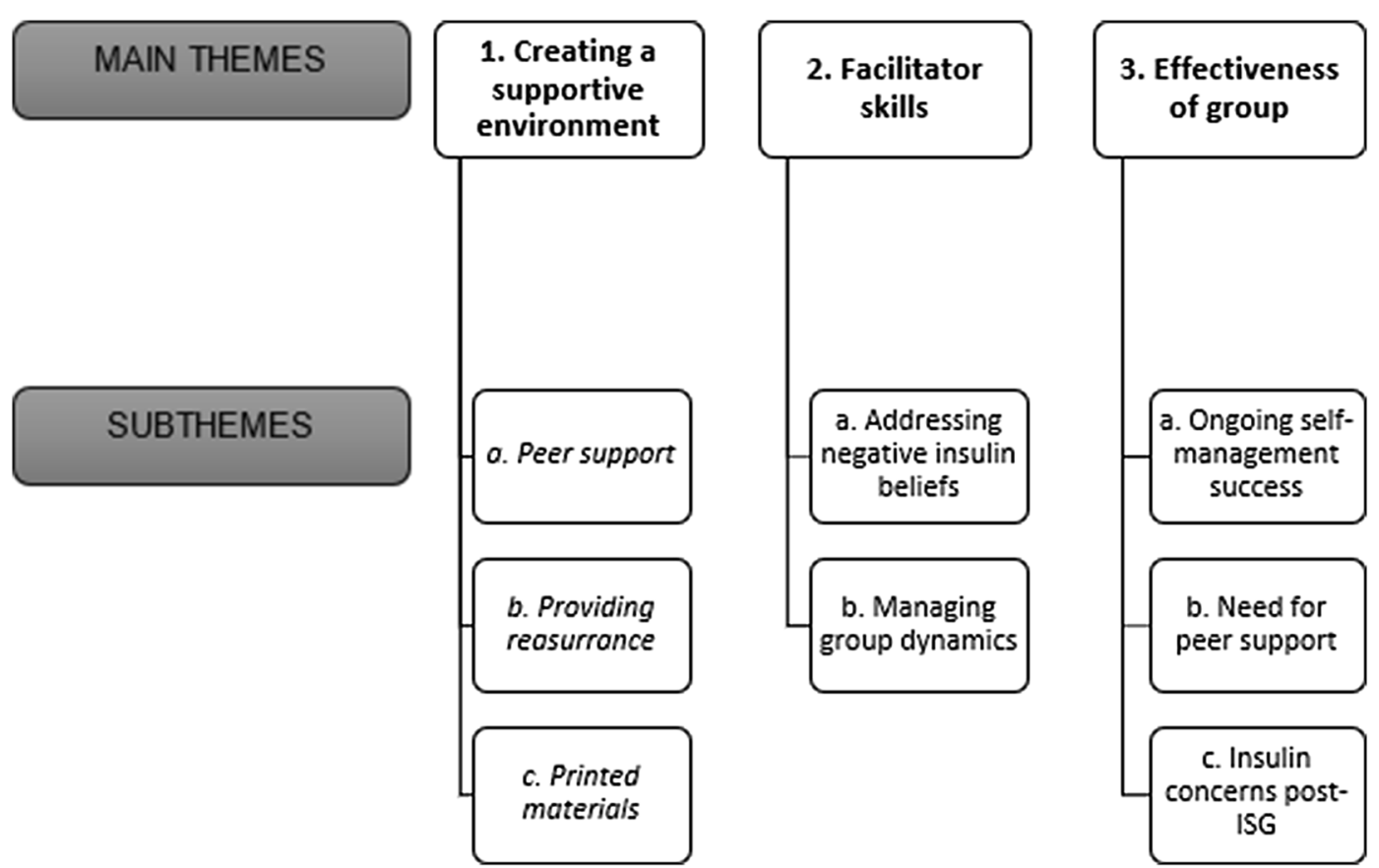

Fig. 1 Summary of themes and subthemes

\section{Peer Support}

Many conveyed that being in a group was a positive supportive experience, e.g. to hear different people's perspective, to share one's own experience, and being with other people with diabetes (quotations are followed by participant number and gender in parentheses):

"...you can come in and then share your experience and also gain from other people's experience..." (13M).

"You feel more comfortable, you are not the only one [with diabetes]...I was happy as well because I'm going to see other people as well" (08F).

Another highlighted a sense of personal failure in relation to having to take insulin for their diabetes but feeling comforted by a range of people in the group being in the same situation as themselves:

"...so thinking, "What have I done wrong?", but when you sit around, you see young ones, old ones, and everybody's been on it [insulin], it's kind of an inspiration" (12M).

\section{Providing Reassurance}

Reassurance was provided by the insulin group facilitator who would deliver important educational information such as frequency of injections:

"Well reassurance from them that it wasn't going to be a big task to take the injections every night and it was only one" (04M).

The type of information was not the only important factor in providing reassurance but the way in which the information was communicated led to feelings of empowerment:

"I was empowered, you know, the nurse explained a lot of things to us" (01F).

\section{Printed Materials}

For some, printed materials which were given to the group to take home, were an informative resource to support the educational content and reinforce knowledge learnt:

"Yes, they are informative, you know, they have a lot of information that you need to know about diabetes and insulin, you know" (06M). 
"The leaflets were just a form of reinforcement, that's what they were" (15M).

Others reported negatively on these resources which led to them being unread or thrown away, one explanation was this was due to being given too many leaflets:

"if you had a lot of papers, you know, some of it might go missing...but few I read honestly" (01F).

"I probably binned them, but they were, they were useful at the time" (10F).

Other interviewees suggested that the printed materials were not suitable for all audiences such as those where English is not their first language:

"lots of information papers but they are too much to read, especially because English is not my language that's why maybe" (02F).

\section{Facilitator Skills}

It was important for facilitators to have the appropriate skills to manage concerns around insulin therapy within the groups. Managing group dynamics could be positively or negatively attributed to the skill of the facilitator.

\section{Addressing Negative Insulin Beliefs}

One approach group facilitators used to address fear of injections was practical demonstrations and practice of injecting which eliminated concerns for some:

"I had a go at doing the injection. And then, you know, I thought oh my God, this is fine" $(01 \mathrm{~F})$.

However, facilitators did not address fears for all, one interviewee described feelings of anxiety which prevented retention of information:

"...of course being human beings we sometimes shut down from things that we fear.... So we don't necessarily take onboard as much as we could do were we not human beings that have fears and anxieties and personalities..." (03F).
In addition, there was one account indicating that the diabetes specialist nurse facilitator lacked skills to support fears around insulin:

"there was one lady who was really frightened...I noticed that the nurse wasn't persuading her or doing any other thing except just explaining what it [insulin] was..." (13M).

\section{Managing Group Dynamics}

An interviewee described the importance of the diabetes specialist nurse facilitator allowing time for everyone's questions and managing different people within the group to check their understanding:

"Because they take a small number of people and the nurses...gives yourself time to talk to people individually and then, you know, some people...take time to digest information but then the nurse has got time to listen to those people and then explain further so that people understand the session" (01F).

There were, however, reports of frustration around listening to other group members' experiences indicating that group dynamics were not well managed in some cases:

“...listening to other people's experience, plenty of time was given so people could go on and on and on, that may be something to manage, yeah, because people can go into their lifetime stories and many of them moved away from the point being discussed" (13M).

In related accounts, a preference for one-toone education was expressed so questions could be answered unlike their experience within a group:

"You know, we're in a group, you can't keep on asking questions when other people have their hands up...if it's like one-toone thing you've been apportioned a time, like fifty minutes I'm going to be with you, ask all the question..." (12M).

There was an indication that people in the group were at different 'levels' including insulin 
experience (i.e. previously on injection therapy) and age; these factors were not controlled within the group setting:

"I'm more experienced than they are.... I've been injecting myself [previously], so it, it was a bit pedestrian for, really it was a bit pedestrian...it wasn't the same for me as it was for these people trying to learn how to inject themselves" (10F).

"...the kind of only daunting thing for me was that when you're seeing a lot of people much, much older around you [in the group]..." (07M).

\section{Effectiveness of Group}

By gauging knowledge and beliefs of people who had attended insulin group education, inferences could be made about the effectiveness of the group. Subthemes which were indicators of effectiveness of the insulin group include ongoing management success, need for more peer support, and insulin concerns post group.

\section{Ongoing Self-Management Success}

Success of insulin self-management post insulin group was highlighted by improvement in blood glucose levels:

“...my sugar levels are down. I'm a happy person" (01F).

However, not all diabetes self-management feedback post insulin group was positive. For example, groups did not appear to take into consideration cultural differences in diet and lifestyle, with one report of need for education around Afro-Caribbean diets and diabetes:

"...with the greatest respect there is the marked difference between a Western diet and Afro-Caribbean and even an Asian diet, there's a marked difference. So...with the best of intentions making a suggestion to somebody from another culture without understanding their own diet, the advice might sound alien..." (15M).
Other self-management techniques which required more attention in insulin groups included injection technique, and describing the different types of insulin:

"I find the actual injection thing, I find it very hard to press it, because you're holding your...you know, and then you have to put it in, I find that very hard..." (09F).

"I thought they should have explained to us why some people, they call it active, instant reacting insulin, why are some people on that and some people on the other one?" (12M).

There was also lack of knowledge around knowing how to react to pseudohypoglycaemia. This is an event of hypoglycaemia symptoms that can occur when blood glucose levels are greater than $3.9 \mathrm{mmol} / \mathrm{L}(70 \mathrm{mg} / \mathrm{dL})$ (i.e. not hypoglycaemic levels) resulting from previous exposure to long-term hyperglycaemia:

"I woke up this morning feeling a bit, I don't know, I haven't felt like this for a long time, I feel dizzy. In fact, I took my, when I was not feeling well, I took my blood to test it. It wasn't even on hypo level, so I don't know why I was feeling like that..." (11F).

\section{Need for More Peer Support}

Need for further peer support beyond the insulin education groups was indicated by wanting more social activities and meeting up with group members living close by:

"But then they can always encourage that little group that's local to each other. I don't know whether you realise it but like there's six of you in this room at the moment that are all within a mile of each other" (03F).

Also, some expressed a desire for follow-up group or 'booster' sessions to refresh content learnt in groups:

"how to put that into refresh my mind for that to come up, plus I used to forget something, very soon I will forget everything, yeah" (14M). 
However, others were content with the original two sessions:

"The two groups were just right" (13M).

Not only face-to-face support was mentioned but one participant also shared their positive experience of peer support via a web support group to ask questions about diabetes and insulin:

"I'm able to contact other people and if I have questions I'm able to post it and have somebody who's had that experience so it's a continuous thing" (13M).

\section{Insulin Concerns Post Group}

There were some positive accounts of insulin therapy such as confidence in insulin efficacy and taking insulin, and improved well-being:

"I felt confident to start it and since then I've been doing it" (06M).

"It's made me, you know, feel myself again" (01F).

However, interviewees did recount a range concerns which remained post insulin group such as injecting for life, hypoglycaemia, where to inject, and weight gain. This suggests that the insulin groups were not effective in eliminating all concerns around insulin therapy:

"Just think about injecting myself for the rest of my life, I think that's one of the biggest disadvantage for me you know" (07M).

"The hypo quite a lot...I feel quite dizzy" $(11 \mathrm{~F})$.

"I'm having a problem with the injection, you know, that is locating areas in my tummy where to inject" (06M).

"I noticed that I put on weight with insulin" (12M).

Another concern from one interviewee was travelling with insulin, which now prevented him from seeing friends as he did not want to take insulin with him:
"Even I go and stay with a friend of mine down in Crawley and since I've been on insulin I haven't been down to see him because I don't want to be taking medication down with me" (04M).

\section{DISCUSSION}

The aim of this qualitative interview study was to identify perceptions of group insulin education for people with type 2 diabetes. Interviews of people with type 2 diabetes who had attended group insulin education in south London revealed three main themes: creating a supportive environment, facilitator skills, and effectiveness of group.

\section{Creating a Supportive Environment}

Social support including peer support is important for improving outcomes in type 2 diabetes $[32,33]$. We found that peer support in insulin group education led to positive experiences as well as reducing personal failure related to starting insulin by being around other people in the same situation.

Previous research indicates that acceptance of insulin therapy is associated with healthcare professional support [34]. Diabetes nurses/educators providing reassurance was found to be beneficial in our analysis. Reassurance was also achieved by providing important educational information as well as the way in which information was communicated to empower the group.

Printed materials were given to group members to support learning. These generated mixed reviews, some finding them informative and others criticising the volume of paperwork. These materials were also difficult for those whose first language was not English. Further consideration is required to make resources equitable for all.

\section{Facilitator Skills}

Previous research has indicated that starting insulin can decrease negative insulin beliefs 
such as fears of hypoglycaemia [35]. However, it is unknown whether this is related to receiving certain types of insulin education or the skill of the diabetes nurse/educator. Our study found that fears of injecting were addressed in group insulin education through practical demonstrations and practising injecting in the group. This is supported by the wider literature where there is evidence that receipt of practical advice, such as insulin injection demonstrations, helps people with type 2 diabetes avoid delays in initiating insulin [36].

However, we also found that not all interviewees were satisfied and communicated that the facilitator lacked skills to support or address their fears and anxiety around insulin therapy. In addition, in some circumstances facilitators did not manage group dynamics well and some participants expressed concerns as some of the diabetes nurses did not answer everyone's questions, and were not effective at managing people at different life stages e.g. level of insulin knowledge and experience or age group. Whilst some diabetes specialist nurses delivering insulin start groups in south London might have had some group education training for other diabetes education groups, e.g. DESMOND (Diabetes Education and Self-Management for Ongoing and Newly Diagnosed), they are often expected to run insulin start groups without formal training. There is no current accredited insulin start groups training in the UK which may account for inconsistences in facilitator skill. Meta-analyses have demonstrated that psychological interventions using cognitive behavioural therapy and counselling can help support people with type 2 diabetes to selfmanage and improve glycaemic control $[37,38]$. Whilst, some of the included studies were delivered to groups of people, they were not specifically related to insulin initiation. However, facilitators trained in these psychological skills might be better equipped to address insulin concerns in a group setting.

\section{Effectiveness of Group}

Previous research related to group type 2 diabetes education has demonstrated improvements in glycaemic control [12-16]. Our findings provide further support for group type 2 diabetes education with interviewees providing accounts of improved blood glucose readings post insulin education group. There were also negative reports including lack of consideration for cultural differences in relation to dietary content. It is important to consider these differences as culturally appropriate education for people with type 2 diabetes is associated with improvement in glycaemic control and knowledge compared with untailored group education [39].

The insulin start group education delivered to participants in this study is not equivalent to structured education (with a manualised evidence-based curriculum); hence this may account for descriptions of missing elements of insulin education such as injection technique, types of insulin and hypoglycaemia awareness in some groups. An insulin education group which is defined as structured education according to UK guidelines $[40,41]$ could eliminate inconsistency in curriculum between groups.

The need for more peer support which was indicated by desire for social activities, group booster sessions and web support might suggest that the insulin group was not entirely successful in terms of providing support necessary to independently self-manage. Nevertheless, additional peer support may help support selfmanagement in the longer term where group diabetes education has previously found to be unsuccessful $[42,43]$.

\section{Strengths and Limitations of Current Research}

We aimed to adopt a reflexive research design by including a multidisciplinary authorship team to allow for a broad understanding of the topic from design, analysis and interpretation of findings. A strength of our findings is the transferability of the results. Ultimately determining the transferability of the results is down to the reader who decides whether they can be applied to another sociocultural setting [44] and this can be aided by applying study results to 
existing theoretical health models. Our study can be applied to the COM-B ('capability', 'opportunity', 'motivation' and 'behaviour') health behaviour model [45]. For example, our theme 'Ongoing self-management success' (theme 3.a) relates to the capability of self-managing with insulin in terms of knowledge and skill. The theme 'Insulin concerns post group' (theme 3.c) relates to the motivation to use insulin therapy (e.g. confidence to inject and plans to do so). Finally, our theme 'Need for more peer support' (theme 3.b) relates to the opportunity to selfmanage with insulin in terms of physical opportunity (e.g. travelling with insulin) or having social support. Furthermore, this supports using the COM-B model to redesign future insulin education interventions.

Although the sample was limited to south London, this area is diverse in terms of ethnicity and socio-economic status and our sampling strategy took this into consideration. Therefore, what is learnt from this population is likely to be transferable to other areas of the UK and western Europe. We considered recruitment of majority Black African or Caribbean ethnic group an advantage due to the large population of people from non-white European ethnicity in south London. Even though the minority of our sample was of South Asian ethnicity, difficulty in recruiting this demographic was anticipated owing to previous research of people with type 2 diabetes from south London [17, 46]. This group has a low prevalence compared with other ethnic groups; therefore, there was a smaller pool of people from this ethnic group to sample who had attended an insulin start group. Although we felt that audiotapes were accurately transcribed and there was consistency between the data presented and findings, a potential limitation is that we did not return transcripts to participants for comment or correction, and participants did not provide feedback on findings. In future research these additional measures could be taken to determine whether participants provide further insight post interview.

\section{CONCLUSIONS}

This study highlights the importance of peer support and facilitator skill in creating a positive supportive environment in group insulin education. However, diabetes specialist nurses delivering group insulin education may need to develop psychological skills to enhance patient communication, better manage group dynamics, and to address concerns around insulin therapy. In addition, insulin group content and supporting printed materials need to be further developed to be equitable to all regarding language and cultural differences. Follow-up peer support could be useful in optimising ongoing insulin self-management. This study provides a foundation for developing structured insulin education groups, and subsequently informing standardised treatment guidance around insulin education.

\section{ACKNOWLEDGEMENTS}

We would like to thank the people with type 2 diabetes who were interviewed for this study, and the General Practices for accommodating us whilst conducting interviews.

Funding. This paper presents independent research funded by the United Kingdom's National Institute for Health Research (NIHR) under its Individual Award Programme (Reference Number ICA-SCL-2015-01-002) in addition to being supported by the NIHR Collaboration for Leadership in Applied Health Research and Care south London at King's College Hospital NHS Foundation Trust. The views expressed are those of the authors and not necessarily those of the NHS, the NIHR or the Department of Health. The Rapid Service Fee was funded by the authors.

Authorship. All named authors meet the International Committee of Medical Journal Editors (ICMJE) criteria for authorship for this article, take responsibility for the integrity of the work as a whole, and have given their approval for this version to be published. 
Disclosures. Rebecca Upsher, Maya AllenTaylor, Ilse Reece, Mark Chamley, Khalida Ismail, Angus Forbes and Kirsty Winkley have nothing to disclose.

Compliance with Ethics Guidelines. Ethical approval was obtained by King's College Hospital (ref. 17/LO/0363). Participants were provided with information sheets before commencing the study, were given time to consider the information and ask the researchers questions. They were informed of their right to withdraw at any time. Participants signed a consent form. Personal identifiers were removed and cannot be identified in this report. This study was performed in accordance with the Helsinki Declaration of 1964 and its later amendments.

Data Availability. The datasets generated during and/or analyzed during the current study are available from the corresponding author on reasonable request.

Open Access. This article is distributed under the terms of the Creative Commons Attribution-NonCommercial 4.0 International License (http://creativecommons.org/licenses/ by-nc/4.0/), which permits any noncommercial use, distribution, and reproduction in any medium, provided you give appropriate credit to the original author(s) and the source, provide a link to the Creative Commons license, and indicate if changes were made.

\section{REFERENCES}

1. WHO. World Health Organisation: Global report on diabetes. 2016. https://apps.who.int/iris/bits tream/handle/10665/204871/9789241565257_eng. pdf; jsessionid=11F24E2EC8A9C1F245AA77969BBD 1AA7? sequence=1. Accessed 25 July 2019 .

2. Seuring T, Archangelidi O, Suhrcke M. The economic costs of type 2 diabetes: a global systematic review. Pharmacoeconomics. 2015;33(8):811-31.

3. NCD Risk Factor Collaboration (NCD-RisC). Noncommunicable diseases risk factor collaboration: worldwide trends in diabetes since 1980: a pooled analysis of 751 population-based studies with 4.4 million participants. Lancet. 2016;387(10027): 1513-30.

4. Lean ME, Leslie WS, Barnes AC, et al. Primary careled weight management for remission of type 2 diabetes (DiRECT): an open-label, cluster-randomised trial. Lancet. 2018;391(10120):541-51.

5. Barag SH. Insulin therapy for management of type 2 diabetes mellitus: strategies for initiation and longterm patient adherence. J Am Osteopath Assoc. 2011;111(7 Supplement 5):S13.

6. Donnelly LA, Morris AD, Evans J, Collaboration DM. Adherence to insulin and its association with glycaemic control in patients with type 2 diabetes. J Assoc Phys. 2007;100(6):345-50.

7. Turner RC, Cull CA, Frighi V, Holman RR, Group UPDS. Glycemic control with diet, sulfonylurea, metformin, or insulin in patients with type 2 diabetes mellitus: progressive requirement for multiple therapies (UKPDS 49). JAMA. 1999;281(21): 2005-12.

8. NHS. NHS England: five year forward view. 2014. https://www.england.nhs.uk/wp-content/uploads/ 2014/10/5yfv-web.pdf. Accessed 15 July 2019.

9. DUK. Diabetes specialist nursing 2016 workforce survey. 2016. https://www.diabetes.org.uk/resourcess3/2017-09/Diabetes\%20UK_DSN\%20survey\%2020 16\%20final\%20report_October\%202016.pdf. Accessed 15 July 2019.

10. Rizza RA, Vigersky RA, Rodbard HW, et al. A model to determine workforce needs for endocrinologists in the United States until 2020. J Clin Endocrinol Metab. 2003;88(5):1979-87.

11. Yki-Järvinen H, Juurinen L, Alvarsson M, et al. Initiate insulin by aggressive titration and education (INITIATE): a randomized study to compare initiation of insulin combination therapy in type 2 diabetic patients individually and in groups. Diabetes Care. 2007;30(6):1364-9.

12. Deakin T, Cade J, Williams R, Greenwood D. Structured patient education: the Diabetes X-PERT Programme makes a difference. Diabet Med. 2006;23(9):944-54.

13. Trento M, Gamba S, Gentile L, et al. Rethink Organization to iMprove Education and Outcomes (ROMEO): a multicenter randomized trial of lifestyle intervention by group care to manage type 2 diabetes. Diabetes Care. 2010;33(4):745-7.

14. Chatterjee S, Davies MJ, Heller S, Speight J, Snoek FJ, Khunti K. Diabetes structured self-management education programmes: a narrative review and 
current innovations. Lancet Diabetes Endocrinol. 2018;6(2):130-42.

15. Loveman E, Frampton GK, Clegg A. The clinical effectiveness of diabetes education models for type 2 diabetes: a systematic review. Health Technol Assess. 2008;12(9):1-136.

16. Scain SF, Friedman R, Gross JL. A structured educational program improves metabolic control in patients with type 2 diabetes. Diabetes Educ. 2009;35(4):603-11.

17. Winkley K, Upsher R, Keij S, Chamley M, Ismail K, Forbes A. Healthcare professionals' views of group structured education for people with newly diagnosed type 2 diabetes. Diabet Med. 2018;35:911-9.

18. Ellis K, Mulnier H, Forbes A. Perceptions of insulin use in type 2 diabetes in primary care: a thematic synthesis. BMC Fam Pract. 2018;19(1):70.

19. Ng C, Lai P, Lee Y, Azmi S, Teo C. Barriers and facilitators to starting insulin in patients with type 2 diabetes: a systematic review. Int J Clin Pract. 2015;69(10):1050-70.

20. Petrak F, Herpertz S, Stridde E, Pfützner A. Psychological insulin resistance in type 2 diabetes patients regarding oral antidiabetes treatment, subcutaneous insulin injections, or inhaled insulin. Diabetes Technol Therap. 2013;15(8):702-10.

21. Peyrot M, Rubin RR, Lauritzen T, Skovlund SE, Snoek FJ, Matthews DR, et al. Resistance to insulin therapy among patients and providers: results of the cross-national diabetes attitudes, wishes, and needs (DAWN) study. Diabetes Care. 2005;28(11): 2673-9.

22. Polonsky WH, Hajos TR, Dain M-P, Snoek FJ. Are patients with type 2 diabetes reluctant to start insulin therapy? An examination of the scope and underpinnings of psychological insulin resistance in a large, international population. Curr Med Res Opin. 2011;27(6):1169-74.

23. Peyrot M, Rubin RR. Behavioral and psychosocial interventions in diabetes: a conceptual review. Diabetes Care. 2007;30(10):2433-40.

24. Brod M, Alolga SL, Meneghini L. Barriers to initiating insulin in type 2 diabetes patients: development of a new patient education tool to address myths, misconceptions and clinical realities. Patient. 2014;7(4):437-50.

25. Taylor CG, Taylor G, Atherley A, Hambleton I, Unwin N, Adams OP. The Barbados insulin matters (BIM) study: barriers to insulin therapy among a population-based sample of people with type 2 diabetes in the Caribbean island of Barbados. J Clin Transl Endocrinol. 2017;8:49-53.

26. Peragallo-Dittko V. Removing barriers to insulin therapy. Diabetes Educ. 2007;33(s3):60S-5S.

27. Korytkowski M. When oral agents fail: practical barriers to starting insulin. Int J Obes Relat Metab Disord. 2002;26(S3):S18.

28. Spain CV, Wright JJ, Hahn RM, Wivel A, Martin AA. Self-reported barriers to adherence and persistence to treatment with injectable medications for type 2 diabetes. Clin Ther. 2016;38(7):1653-64.

29. RCN. Shaping nursing practice and policy. 2012. https://www.rcn.org.uk/documents/publications/ october/pub-004330. Accessed 15 July 2019.

30. Malterud K, Siersma VD, Guassora AD. Sample size in qualitative interview studies: guided by information power. Qual Health Res. 2016;26(13): 1753-60.

31. Braun V, Clarke V. Using thematic analysis in psychology. Qual Res Psychol. 2006;3(2):77-101.

32. Stopford R, Winkley K, Ismail K. Social support and glycemic control in type 2 diabetes: a systematic review of observational studies. Patient Educ Couns. 2013;93(3):549-58.

33. Strom JL, Egede LE. The impact of social support on outcomes in adult patients with type 2 diabetes: a systematic review. Curr Diabetes Rep. 2012;12(6): 769-81.

34. Hassan HA, Tohid H, Amin RM, Bidin MBL, Muthupalaniappen L, Omar K. Factors influencing insulin acceptance among type 2 diabetes mellitus patients in a primary care clinic: a qualitative exploration. BMC Fam Pract. 2013;14(1):164.

35. Hajós TR, Pouwer F, De Grooth R, et al. Initiation of insulin glargine in patients with type 2 diabetes in suboptimal glycaemic control positively impacts health-related quality of life. A prospective cohort study in primary care. Diabet Med. 2011;28(9): 1096-102.

36. Polonsky WH, Fisher L, Hessler D, et al. Identifying solutions to psychological insulin resistance: an international study. J Diabetes Complicat. 2019;33(4):307-14.

37. Ismail K, Winkley K, Rabe-Hesketh S. Systematic review and meta-analysis of randomised controlled trials of psychological interventions to improve glycaemic control in patients with type 2 diabetes. Lancet. 2004;363(9421):1589-97. 
38. Alam R, Sturt J, Lall R, Winkley K. An updated metaanalysis to assess the effectiveness of psychological interventions delivered by psychological specialists and generalist clinicians on glycaemic control and on psychological status. Patient Educ Couns. 2009;75(1):25-36.

39. Hawthorne K, Robles Y, Cannings-John R, Edwards A. Culturally appropriate health education for type 2 diabetes in ethnic minority groups: a systematic and narrative review of randomized controlled trials. Diabet Med. 2010;27(6):613-23.

40. NICE. NG28: type 2 diabetes in adults: management. 2011. https://www.nice.org.uk/guidance/ qs6/resources/diabetes-in-adults-pdf-58299425989. Accessed 16 July 2019.

41. SIGN. Management of diabetes: a national clinical guideline. 2017. https://www.sign.ac.uk/assets/ sign116.pdf. Accessed 16 July 2019.

42. Khunti K, Gray LJ, Skinner T, et al. Effectiveness of a diabetes education and self management programme (DESMOND) for people with newly diagnosed type 2 diabetes mellitus: three year follow-up of a cluster randomised controlled trial in primary care. Brit Med J. 2012;344:e2333.

43. Rankin D, Cooke DD, Elliott J, Heller SR, Lawton J. Supporting self-management after attending a structured education programme: a qualitative longitudinal investigation of type 1 diabetes patients' experiences and views. BMC Public Health. 2012;12(1):652.

44. Kuper A, Lingard L, Levinson W. Critically appraising qualitative research. BMJ. 2008;337: a1035.

45. Michie S, Van Stralen MM, West R. The behaviour change wheel: a new method for characterising and designing behaviour change interventions. Implement Sci. 2011;6(1):42.

46. Winkley K, Evwierhoma C, Amiel S, Lempp $\mathrm{H}$, Ismail K, Forbes A. Patient explanations for nonattendance at structured diabetes education sessions for newly diagnosed type 2 diabetes: a qualitative study. Diabet Med. 2015;32(1):120-8. 